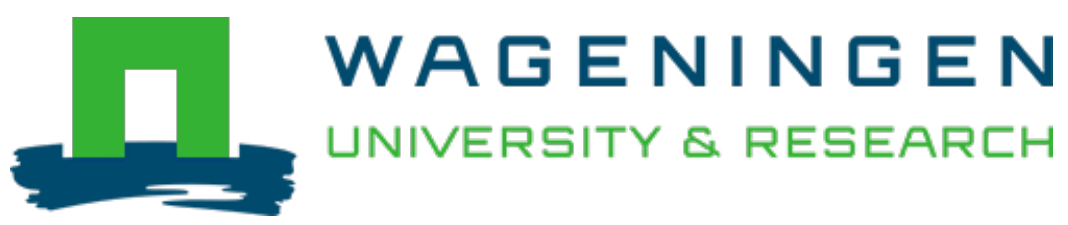

\title{
Milling characteristics and distribution of phytic acid and zind in long-, medium- and short-grain rice
}

\author{
Journal of Cereal Science \\ Liang, J.; Tsuji, K.; Nakano, K.; Nout, M.J.R.; Hamer, R.J. \\ https://doi.org/10.1016/j.jcs.2007.08.003
}

This publication is made publicly available in the institutional repository of Wageningen University and Research, under the terms of article $25 \mathrm{fa}$ of the Dutch Copyright Act, also known as the Amendment Taverne. This has been done with explicit consent by the author.

Article 25 fa states that the author of a short scientific work funded either wholly or partially by Dutch public funds is entitled to make that work publicly available for no consideration following a reasonable period of time after the work was first published, provided that clear reference is made to the source of the first publication of the work.

This publication is distributed under The Association of Universities in the Netherlands (VSNU) 'Article $25 \mathrm{fa}$ implementation' project. In this project research outputs of researchers employed by Dutch Universities that comply with the legal requirements of Article $25 \mathrm{fa}$ of the Dutch Copyright Act are distributed online and free of cost or other barriers in institutional repositories. Research outputs are distributed six months after their first online publication in the original published version and with proper attribution to the source of the original publication.

You are permitted to download and use the publication for personal purposes. All rights remain with the author(s) and / or copyright owner(s) of this work. Any use of the publication or parts of it other than authorised under article $25 \mathrm{fa}$ of the Dutch Copyright act is prohibited. Wageningen University \& Research and the author(s) of this publication shall not be held responsible or liable for any damages resulting from your (re)use of this publication.

For questions regarding the public availability of this publication please contact openscience.library@wur.nl 


\title{
Milling characteristics and distribution of phytic acid and zinc in long-, medium- and short-grain rice
}

\author{
Jianfen Liang ${ }^{\mathrm{a}, \mathrm{b}}$, Zaigui $\mathrm{Li}^{\mathrm{a}}$, Kouichi Tsujic, Kazuhiko Nakano ${ }^{\mathrm{c}}$, \\ M.J. Robert Nout ${ }^{\mathrm{b}, *}$, Robert J. Hamer ${ }^{\mathrm{b}}$ \\ ${ }^{a}$ College of Food Science and Nutritional Engineering, China Agricultural University, Beijing 100083, PR China \\ ${ }^{\mathrm{b}}$ Department of Agrotechnology and Food Sciences, Wageningen University, Wageningen, The Netherlands \\ ${ }^{\mathrm{c}}$ Department of Applied Chemistry, Graduate School of Engineering, Osaka City University, Osaka 558-8585, Japan
}

Received 21 March 2007; received in revised form 22 July 2007; accepted 9 August 2007

\begin{abstract}
Milling and polishing are important operations during the production of white rice. The degree of milling and polishing has a significant effect on the nutritional aspects of white rice, especially on minerals, due to a non-uniform distribution of nutrients in the kernel. Information on the distribution of nutrients in rice will greatly help in understanding the effect of milling and aid in designing procedures that improve technological and sensory properties of rice while retaining its essential nutrients as much as possible. In this study, three kernel shapes (short-, medium- and long-grain) of rice were selected for the study of milling characteristics and distribution of zinc $(\mathrm{Zn})$ and phytic acid using abrasive milling and X-ray fluorescent microscope imaging approaches.

Milling characteristics differed with kernel shapes and cultivars. Mass loss $(y, \%)$ correlated well with milling duration $(x, s)$ and was fitted using a polynomial equation of $y=a x^{2}+b x+c\left(R^{2}=0.99\right)$. Different kernel shapes of rice resulted in different patterns. Breakage in milling increased with longer duration of milling. The relation between breakage $(y, \%)$ and milling duration $(x, s)$ fitted the exponential equation $y=a \mathrm{e}^{b x}$. Levels of phytic acid, as well as $\mathrm{Zn}$, decreased with prolonged milling. Phytic acid decreased at a higher rate than $\mathrm{Zn}$. The analysis of different milling runs showed that the concentration of phytic acid decreased from the surface region inward, whereas X-ray fluorescent images indicated that the highest concentration of phosphorus was at the interface of the embryo and perisperm.

Our results help in understanding the milling characteristics of different rice cultivars. Understanding these characteristics offers opportunities to optimize milling procedures for maximum phytate removal at minimum mineral losses and yield loss.
\end{abstract}

(C) 2007 Elsevier Ltd. All rights reserved.

Keywords: Mass loss; Breakage; Rice kernel; Distribution; Abrasive methods; X-ray fluorescent microscope imaging

\section{Introduction}

Rice is one of the important cereals in the world. It is commonly used as milled (white) rice produced by removing the hull and bran layer of the rough rice kernel

\footnotetext{
Abbreviations: B37, Bijing 37; G30, Ganwanxian 30; KSA, kernel surface area; PA, phytic acid; PC, protein content; RLW, ratio of length to width; TKW, thousand-kernel weight; YBR, yield of brown rice; Z752, Zhongyou 752; Zn, zinc

*Corresponding author. Laboratory of Food Microbiology, Bomenweg 2, 6703 HD Wageningen, The Netherlands. Tel.: + 31317482834 ; fax: +31317484978 .

E-mail address: Rob.Nout@wur.nl (M.J.R. Nout).
}

(paddy) (Perdon et al., 2001). Brown rice (hulled rice) is composed of surface bran (6-7\% by weight), endosperm $(\approx 90 \%)$ and embryo $(2-3 \%)$ (Chen et al., 1998). White rice is referred to as milled, polished or whitened rice when $8-10 \%$ of mass (mainly bran) has been removed from brown rice (Kennedy et al., 2002). During milling, brown rice is subjected to abrasive or friction pressure to remove bran layers resulting in high, medium or low degrees of milling depending on the amount of bran removed (Chen and Siebenmorgen, 1997; Chen et al., 1998). Milling brings about considerable loss of nutrients and affects the edible properties of milled rice (Chen et al., 1998; Doesthale et al., 1979). As most cereals, rice does not show a homogeneous 
structure from its outer (surface) to inner (central) portions (Itani et al., 2002). As a consequence, information on the distribution of nutrients will greatly help in understanding the effect of milling and aid in improving sensory properties of rice while retaining its essential nutrients as much as possible.

Depending on the extent of milling, changes of some nutrients, such as surface lipids (Chen et al., 1998; Perdon et al., 2001), protein (Chen et al., 1998; Heinemann et al., 2005), physical properties such as rice paste viscosity (Perdon et al., 2001) and sensory quality of milled rice, including taste (Park et al., 2001; Tran et al., 2004), have been reported. Effect of milling on some macro- and microelements, e.g., iron, magnesium, phosphorus and phytic acid (PA), have also been studied (Bryant et al., 2005). Early studies described the effect of milling on minerals or distribution of minerals according to approximate milling degrees, such as lightly milled, reasonably milled and well milled, or as fractions I, II and III, respectively (Kennedy and Schelstraete, 1975; Song et al., 1988; Tabekhia and Luh, 1979). These authors did not provide detailed information about the distribution of these nutrients in rice kernels. Itani et al. (2002) reported the distribution of some nutrients in more detail, although PA and trace minerals were not included. Studies on Indian rice indicated that the extent of milling had a significant effect on loss of magnesium and calcium, but not on phosphorus and trace minerals $(p<0.05)$ (Bajaj et al., 1989). Recently, $\mathrm{X}$-ray fluorescent microscopy techniques were developed and applied to map the distribution of minerals such as magnesium, potassium, phosphorus, calcium and sulphur in quinoa seeds (Emoto et al., 2004; Konishi et al., 2004).

Considering world-wide deficiencies of iron and $\mathrm{Zn}$, our ultimate aim is to improve the bioavailability of these minerals by reducing insoluble mineral-phytate complexes, and fortification if desired. As the $\mathrm{Zn}$-phytate complex is very stable (Vasca et al., 2002), we focussed on $\mathrm{Zn}$ as a target mineral. Our previous study indicated that $\mathrm{Zn}$ and phytate contents in Chinese rice cultivars cover a broad range (Liang et al., 2007). The purpose of the present study was to compare the milling characteristics and the distribution of $\mathrm{Zn}$ and PA in long-, medium- and shortgrain kernels of rice from China, with a view to optimize for maximum phytate removal at minimum loss of $\mathrm{Zn}$. Precision abrasive milling was used to obtain a range of milling degrees, and X-ray imaging methods to map the distribution of different minerals. The degree of milling for specific rice cultivars could be optimized for maximum removal of PA, maximum retention of $\mathrm{Zn}$ and appropriate whiteness to satisfy consumer expectations for white rice.

\section{Materials and methods}

\subsection{Paddy rice and characteristics}

Based on our survey of the variation of PA and minerals in rice cultivars cultivated in China (Liang et al., 2007), three cultivars namely Ganwanxian 30 (G30), Zhongyou 752 (Z752) and Bijing 37 (B37) having different levels of $\mathrm{PA}$ and minerals were selected. According to the industrial standard of China, the three cultivars were classified as long-, medium- and short-grain, respectively (CHISA, 2002). G30 and Z752 were obtained from the Jiangxi Seeds Company, and B37 from the Academy of Agricultural Science of Guizhou. All paddies were harvested during the autumn of 2003 and were stored dry and cool $\left(\sim 15^{\circ} \mathrm{C}\right)$ less than 90 days before processing and analysis. General characteristics, including crude protein content (PC), yield of brown rice (YBR), breakage from hulling, shape i.e., ratio of length to width (RLW), kernel surface area (KSA) and thousand-kernel weight (TKW), are presented in Table 1.

Table 1

General characteristics of brown rice samples

\begin{tabular}{|c|c|c|c|c|c|c|c|c|}
\hline Cultivar & Collection & $\begin{array}{l}\text { PC } \\
\left(\mathrm{g} 100 \mathrm{~g}^{-1}\right)^{\mathrm{a}}\end{array}$ & Length (mm) & $\mathrm{RLW}^{\mathrm{b}}$ & $\operatorname{KSA}\left(\mathrm{mm}^{2}\right)^{\mathrm{c}}$ & TKW $(g)^{d}$ & $\begin{array}{l}\text { YBR } \\
(\%)^{\mathrm{e}}\end{array}$ & $\begin{array}{l}\text { Breakage } \\
(\%)^{\mathrm{f}}\end{array}$ \\
\hline Bijing 37 (Yu et al., 2001) & Guizhou & 8.8 & 5.2 & 1.8 & 68 & 25.5 & 80.6 & 3.7 \\
\hline $\begin{array}{l}\text { Zhongyou } 752 \text { (Centre of } \\
\text { China Crop Science and } \\
\text { Technology, 2006) }\end{array}$ & Jiangxi & 10.9 & 6.4 & 2.8 & 50 & 26.5 & 71.9 & 16.2 \\
\hline $\begin{array}{l}\text { Gangwanxian } 30 \\
\text { (Information of Jiangxi } \\
\text { foodstuff-oil and soil- } \\
\text { fertilizer, 2006) }\end{array}$ & Jiangxi & 8.5 & 7.6 & 3.4 & 52 & 27.6 & 73.6 & 28.0 \\
\hline
\end{tabular}

\footnotetext{
${ }^{\mathrm{a}} \mathrm{PC}$, protein contents (provided by supplier, see reference).

${ }^{\mathrm{b}} \mathrm{RLW}$, ratios of length to width (analysed in this study).

${ }^{\mathrm{c}} \mathrm{KSA}$, kernel surface area, assumed that the shape of integral kernels were separated into two semi-sphere and a cylinder. Surface area was calculated with $4 \times(\text { width } / 2)^{2} \times \pi+0.9 \times \pi \times$ width $\times$ length (analysed in this study).

${ }^{\mathrm{d}} \mathrm{TKW}$, thousand-kernel weight (provided by supplier, see reference).

${ }^{\mathrm{e}} \mathrm{YBR}$, yield of brown rice, on wet mass basis.

${ }^{\mathrm{f}}$ Breakage caused by dehulling, percentage of broken brown rice weight to total brown rice weight (analysed in this study).
} 


\subsection{Hulling and milling}

Paddy was dehusked with a lab-scale hulling machine (THU-35C, Satake, Japan). Each cultivar was assessed in triplicates for TKW, YBR and breakage from hulling.

Only intact brown rice kernels were used for subsequent milling experiments. About $30( \pm 1) \mathrm{g}$ of brown rice were milled for the duration of $6,10,20,30,45,60,90,180$ and $300 \mathrm{~s}$, respectively, with a lab-scale milling machine (TM 05C, Satake, Japan) to obtain rice milled to different degrees. Each milling treatment (duration) was performed in triplicates. Yields of white rice and breakage from milling were measured. After milling, whole milled rice kernels (head rice) were separated, and then ground with grinder (HY-04B, Beijing Xinhuanya, China) to pass a $1 \mathrm{~mm}$ sieve, and dried at $100^{\circ} \mathrm{C}$ till constant weight. Dried rice flour was kept in sealed plastic bags at $4{ }^{\circ} \mathrm{C}$ until chemical analysis.

\subsection{Zinc $(\mathrm{Zn})$ determination}

Samples of $0.5 \mathrm{~g}$ (accuracy $0.1 \mathrm{mg}$ ) dried rice flour were digested using a microwave laboratory system (Milestone, Italy) with nitric acid $\left(\mathrm{HNO}_{3}\right.$, reagent grade) and hydrogen peroxide $\left(\mathrm{H}_{2} \mathrm{O}_{2}\right.$, analytical reagent, Beijing Chemical Works, China) as described by D'llio et al. (2002). Contents of $\mathrm{Zn}$ in solutions were measured with a Vario 6 Atomic Absorption System (Analytik Jena, Germany). Each sample was digested and measured in triplicates.

\section{4. $P$ A determination}

PA levels in brown rice and milled rice were determined after extraction in $100 \mathrm{~g} \mathrm{~L}^{-1} \mathrm{Na}_{2} \mathrm{SO}_{4}-\mathrm{HCl}(1.2 \%)$ concentration on an anion exchange column, and were analysed spectrophotometrically at $500 \mathrm{~nm}$ after reacting with a $0.03 \% \mathrm{FeCl}_{3}$ solution containing $0.3 \%$ sulfosalicylic acid, according to Ma et al. (2005). All materials were analysed in triplicates.

\subsection{Sample preparation for SEM}

Rice kernels were longitudinally mounted in a brass cylindrical sample holder with carbon conductive glue (Leit-C, Neubauer Chemicalien, Germany). The samples were placed in a sample holder in an ultra microtome (Reichert Ultracut E/FC4D) and cut. These samples were first planed with a glass knife, after which the surface was planed with a diamond knife (Histo no trough, $8 \mathrm{~mm} 45^{\circ} \mathrm{C}$, Drukker International, The Netherlands). This method is based on Nijsse and Van Aelst (1999).

\subsection{X-ray fluorescent imaging}

X-ray elemental maps were obtained with a micro-X-ray fluorescence instrument developed at Osaka City University (Emoto et al., 2004). The X-ray tube (MCBM 50-0.6B, rtw, Germany) with Mo target was operated at $50 \mathrm{kV}$ and $0.45 \mathrm{~mA}$. The tube was installed into an $X$-ray tube shield holder equipped with an $\mathrm{X}-\mathrm{Y}-\mathrm{Z}$ positional device, where the polycapillary $X$-ray lens was attached. The polycapillary lens was designed and manufactured at Beijing Normal University. The length, input focal distance, and output focal distance were designed to be 50,34 and $16 \mathrm{~mm}$, respectively. A spot size of about $40 \mathrm{~mm}$ was obtained at a focal point. A silicon drift X-ray detector (SDD, X-Flash Detector, Type 1201, Rontec, Germany; sensitive area: $10 \mathrm{~mm}^{2}$, energy resolution: $<150 \mathrm{eV}$ at $5.9 \mathrm{keV}$ ) was suspended using a down-looking geometry. The sample stage was placed on the $\mathrm{X}-\mathrm{Y}-\mathrm{Z}$ stage [YA05A$\mathrm{R} 1$ ( $\mathrm{X}-\mathrm{Y}$ stage) and ZA07AR3S ( $\mathrm{Z}$ stage); Kohzu precision, Japan], which was controlled by stepping motors driven by a computer. To control the sample stage, motor drivers and a motor controller (NT2400, Laboratory Equipment Co., Japan) were applied. An SDD signal was analysed by a multi-channel analyser (NT2400/MCA, Laboratory Equipment Co., Japan). To confirm the position of the sample, a visible CCD camera was also installed.

\subsection{Statistical analysis}

Where appropriate, data were presented as means with standard deviation, or by error bars. Significance of differences was tested by two-tailed $t$-tests.

\section{Results and discussion}

\subsection{Milling characteristics}

For the miller, the main quality characteristic of rice is related to the amount of material that needs to be removed to obtain white rice. During the abrasion of rice, not only the outer layers of the kernels are removed, but also kernels are broken. These are also considered a loss. We therefore defined milling characteristics as the mass loss due to bran removal, and breakage during milling. The milling characteristics for the rice cultivars used in this study are shown in Figs. 1(a) and (b).

Figs. 1(a) and (b) show the loss of mass, and breakage, with increasing milling time. For the three cultivars tested, mass losses (Fig. 1a) were similar: with increasing milling duration more of the outer layers is removed. Loss rates become less at longer milling times. The relation of mass loss $(y, \%)$ vs. duration of milling $(x, s)$ fitted a polynomial equation of $y=a x^{2}+b x+c\left(R^{2}=0.99\right)$, as was observed in other studies (Perdon et al., 2001; Singh Gujral et al., 2002). Different kernel shape of rice resulted in different patterns. Z752 had a higher mass loss (Fig. 1a) at each milling time. To achieve a mass loss of $2 \%$, it took less than $10 \mathrm{~s}$ for Z752, and about $20 \mathrm{~s}$ for B37 and G30, respectively. Generally, in order to obtain white rice, about $10-15 \%$ of mass is removed from the outer layers. In this study, Z752 required the shortest duration of milling to obtain white 
a
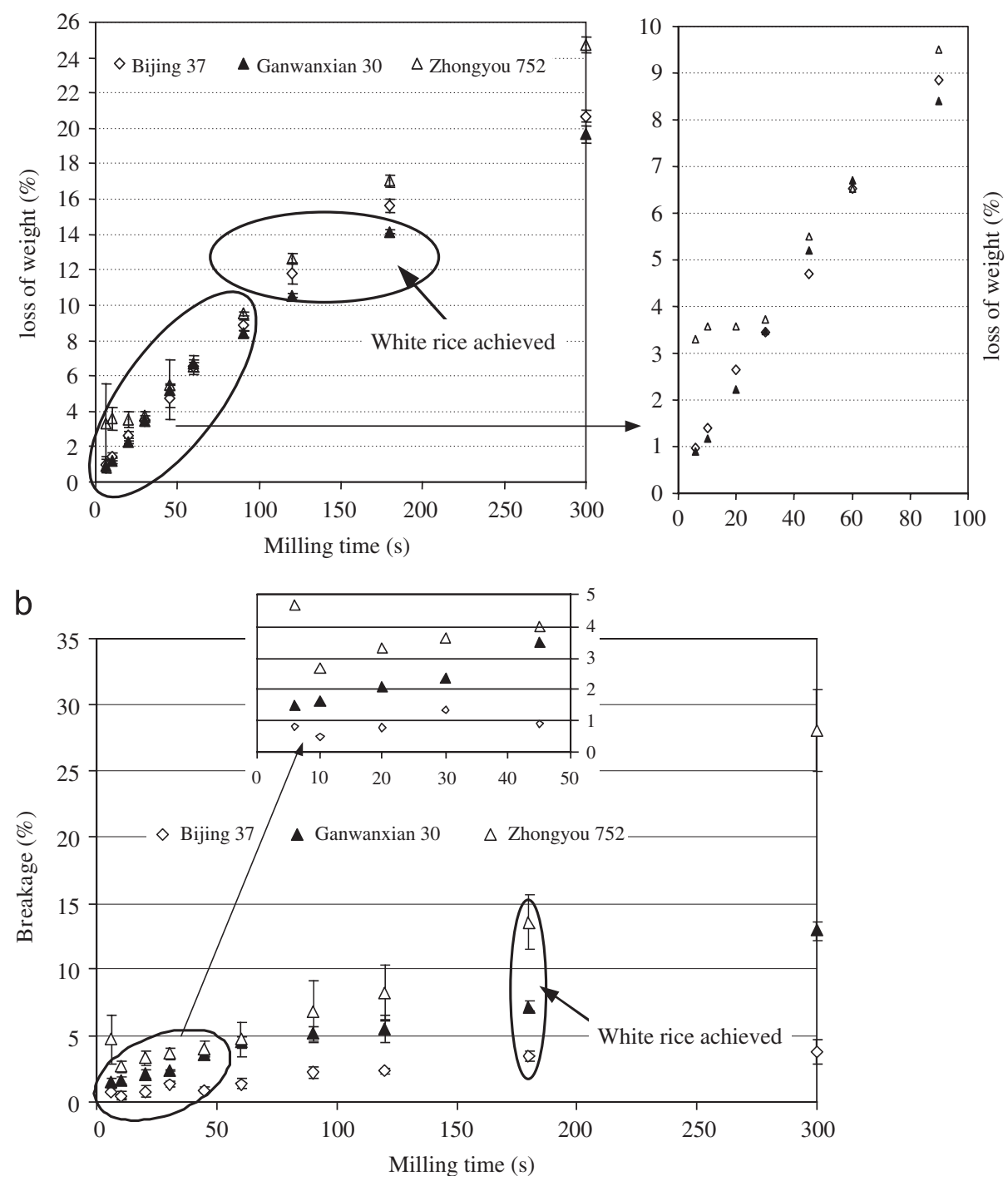

Fig. 1. (a) Mass loss during milling and (b) breakage during milling.

rice, followed by B37 and G30. The differences among mass loss patterns of the three cultivars might be related to the removal of the embryo. Visual inspection to check the removal of the embryo from brown rice during milling revealed a large variation between the different rice cultivars. Under our experimental milling conditions, one-third of the kernels of Z752 and B37 had lost their embryo after $30-45 \mathrm{~s}$ milling, corresponding to a mass loss of $3.5-4.5 \%$, whereas more than $90 \%$ of the kernels had lost their embryo after $90 \mathrm{~s}$ milling, at mass loss of $8.5-9.5 \%$. For G30, about $30 \%$ of kernels had lost their embryo at $2 \%$ mass loss ( $20 \mathrm{~s}$ milling), whereas after $45 \mathrm{~s}$ milling, most kernels had lost their embryo at a mass loss of $5 \%$.

Rice breakage was quantified as the weight of broken rice expressed as a percentage of the total weight of milled rice (Chen et al., 1998). Breakage of the three cultivars was similar (Fig. 1b), increasing with longer duration of milling. The relation between breakage $(y, \%)$ and milling duration $(x, s)$ fitted the exponential equation $y=a \mathrm{e}^{b x}$. The different cultivars had different $a$ and $b$ values with a $R^{2}$ ranging from 0.76 to 0.95 . Of the three cultivars, Z752 had the highest breakage values, and B37 had the lowest at each time interval. After $90 \mathrm{~s}$ milling, breakage of Z752 had reached $30 \%$, while breakage of B37 was still low (about $5 \%)$. The amount of broken kernels of long-grain in the present study was of a similar magnitude as of long-grain rice reported elsewhere (Chen et al., 1998).

\section{2. $P A$ and $Z n$ levels}

$\mathrm{PA}$ and $\mathrm{Zn}$ levels in rice after increasing degrees of milling are presented in Table 2.

Levels of PA and $\mathrm{Zn}$ decreased with prolonged milling. Although it has been observed earlier (Itani et al., 2002) that all minerals (including phosphorus) decrease from the outermost fraction, it appears here that PA levels decrease at a higher rate than those of $\mathrm{Zn}$. 
Table 2

Contents of phytic acid and zinc in milled rice*

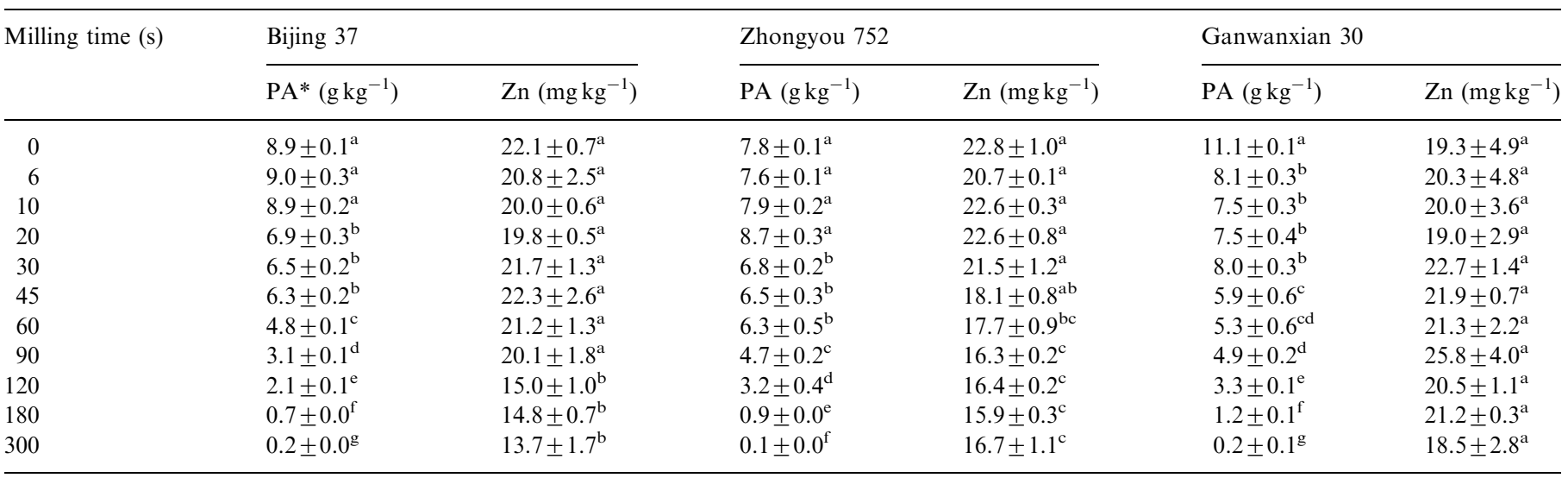

*All data are based on dry mass weight and are presented as average \pm standard deviations $(n=3)$. Within columns, different superscripts indicate significant differences $(P<0.05$, two-tailed $t$-test $)$

PA levels in brown rice of B37, Z752 and G30 were 8.9, 7.8 and $11.1 \mathrm{~g} \mathrm{~kg}^{-1}$, respectively. These values differ from our previous results (Liang et al., 2007) probably due to differences of cultivating environments and agricultural practice (Liu et al., 2005a). G30 had the highest PA content in raw brown rice and this decreased quickly during milling. After $30 \mathrm{~s}$ milling, PA levels in milled rice of B37 and $\mathrm{Z} 752$ were at the same level $\left(7 \mathrm{~g} \mathrm{~kg}^{-1}\right)$ although they started at different initial values, and it was $8 \mathrm{~g} \mathrm{~kg}^{-1}$ in G30 after the same milling time. After $120 \mathrm{~s}$ milling (duration considered to be optimum in commercial milling of white rice), PA in G30 and $\mathrm{Z} 752$ were still at the level of $3.2 \mathrm{~g} \mathrm{~kg}^{-1}$, higher than in B37 $\left(2.0 \mathrm{~g} \mathrm{~kg}^{-1}\right)$. After $300 \mathrm{~s}$ milling, PA in all cultivars were at the level of $0.2 \mathrm{~g} \mathrm{~kg}^{-1}$. PA levels in brown rice decreased at a similar rate as reported elsewhere (Doesthale et al., 1979) for phosphorus.

The $\mathrm{Zn}$ levels in the brown rice cultivars studies did not decrease significantly $\left(22.1,22.8\right.$ and $19.3 \mathrm{mg} \mathrm{kg}^{-1}$, respectively), and even after $30 \mathrm{~s}$ milling (corresponding to a mass loss of about $5 \%$ ), the $\mathrm{Zn}$ levels in all cultivars of milled rice were still at the same level of brown rice. The biggest lost of $\mathrm{Zn}$ in $\mathrm{Z752}$ occurred after $45 \mathrm{~s}$ milling, and in B37 after $120 \mathrm{~s}$ milling. However, in G30, up to $120 \mathrm{~s}$ milling did not affect its $\mathrm{Zn}$ level, a phenomenon that has been previously reported (Juliano, 1972; Villareal et al., 1991). With some milled rice samples even higher $\mathrm{Zn}$ levels were reported than in the initial brown rice (Heinemann et al., 2005). In the three cultivars studied here, $\mathrm{Zn}$ levels after $300 \mathrm{~s}$ milling were $4-38 \%$ lower than that of initial values.

\subsection{Location and distribution of $P A$ and $Z n$ in brown rice}

In order to visualize the distribution of $\mathrm{PA}$ and $\mathrm{Zn}$ in brown rice, $\mathrm{X}$-ray fluorescent microscope imaging techniques were used. Images of location of PA (indicated as phosphorus, P) and $\mathrm{Zn}$ obtained with X-ray fluorescent scanning, as well as the distribution of PA and $\mathrm{Zn}$ in brown rice kernels obtained by abrasive milling are shown in Figs.
$2 \mathrm{a}-\mathrm{c}$ and demonstrate the location of $\mathrm{P}$ and $\mathrm{Zn}$ in rice kernels.

In all three cultivars, the density of phosphorus decreased from the surface region inward. This agrees with data from abrasive milling experiments (Bryant et al., 2005). The peripheral embryo region did not show high phosphorus intensities, whereas much higher densities were observed near or at the interface of embryo and endosperm. We observed that whereas in B37 (Fig. 2a) and G30 (Fig. 2c), the distribution of phosphorus was similar; the distribution in Z752 (Fig. 2b) was different, having no distinct layer with higher phosphorus concentration. Notably, at the side of the embryo, we could not observe the high density of phosphorus as observed in Figs. 2(a) and (c). The distribution of phosphorus in the rice kernels suggested that at least the outer layer should be removed if we want to significantly decrease PA in milled rice, since $70-85 \%$ of phosphorus occurs as $\mathrm{PA}$ in rice.

The location of $\mathrm{Zn}$ in the three cultivars was similar. All three cultivars had the highest density of $\mathrm{Zn}$ in the embryo whereas $\mathrm{Zn}$ was relatively evenly distributed in the other regions. This helps us to understand earlier reports, that milling degrees higher than $10 \%$ had little effect on $\mathrm{Zn}$ levels in milled rice (Bryant et al., 2005). The location of $\mathrm{Zn}$ indicates that it may be beneficial to retain more embryo to obtain higher final levels of $\mathrm{Zn}$.

We observed an inverse relation: $y=a-b x(a=7.7-8.3$, $\left.b=0.03, R^{2}=0.82-0.91\right)$ between PA levels $\left(y, \mathrm{mg} \mathrm{g}^{-1}\right)$ and milling duration $(x, s)$ (Figs. 2a-c). This relation shows some similarity with that between milling degree and surface lipid, and phenolic acids observed elsewhere (Perdon et al., 2001; Zhou, 2003). In B37 and Z752, about $23-33 \%$ of total PA was located in the surface outer layer of kernel $(2-3 \%$ weight per cent of brown rice). In all cultivars, about $23-25 \%$ of total PA was located in the subsurface layer, which accounted for $3.4-4.5 \%$ of total weight. Less than $2 \%$ of total PA was located in the $75-80 \%$ of central portion of kernel. The remaining 
a
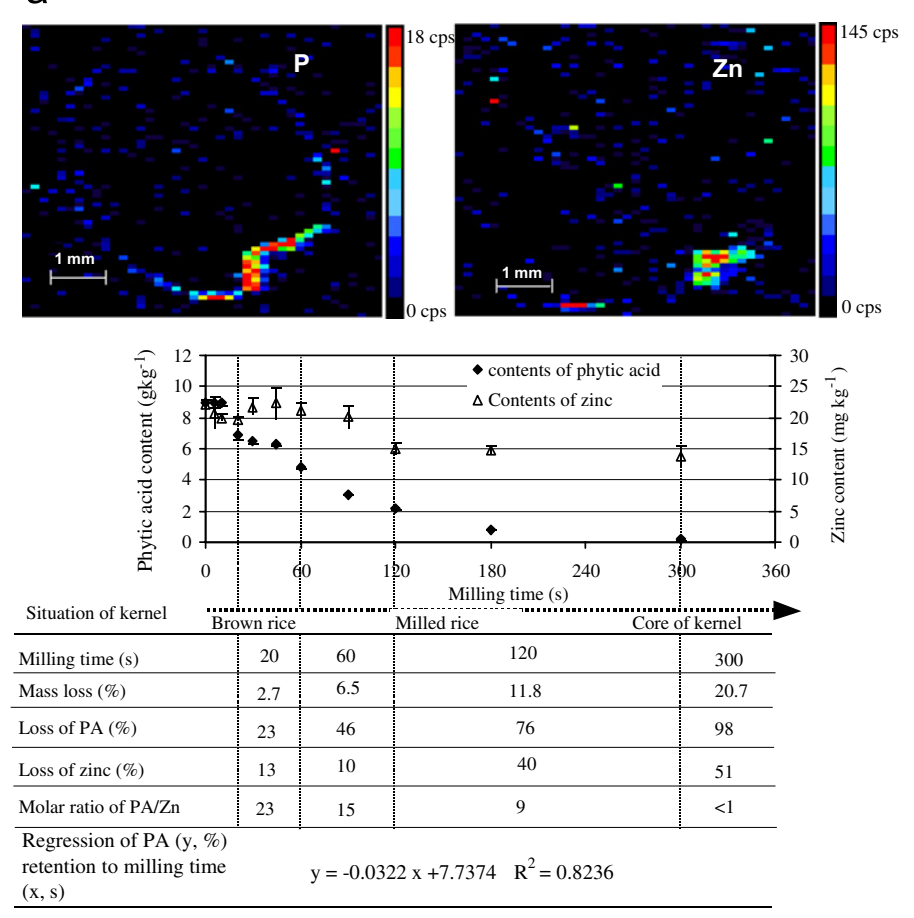

C
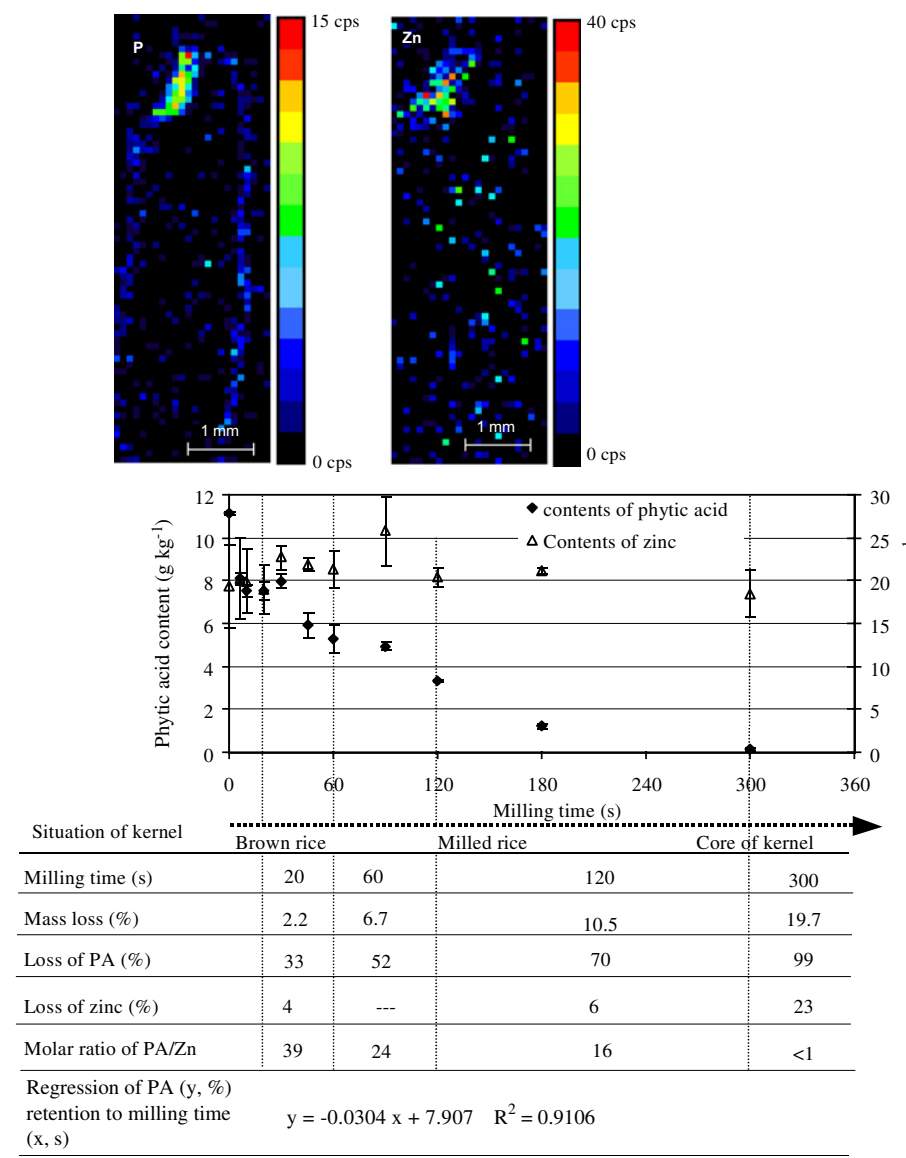

b
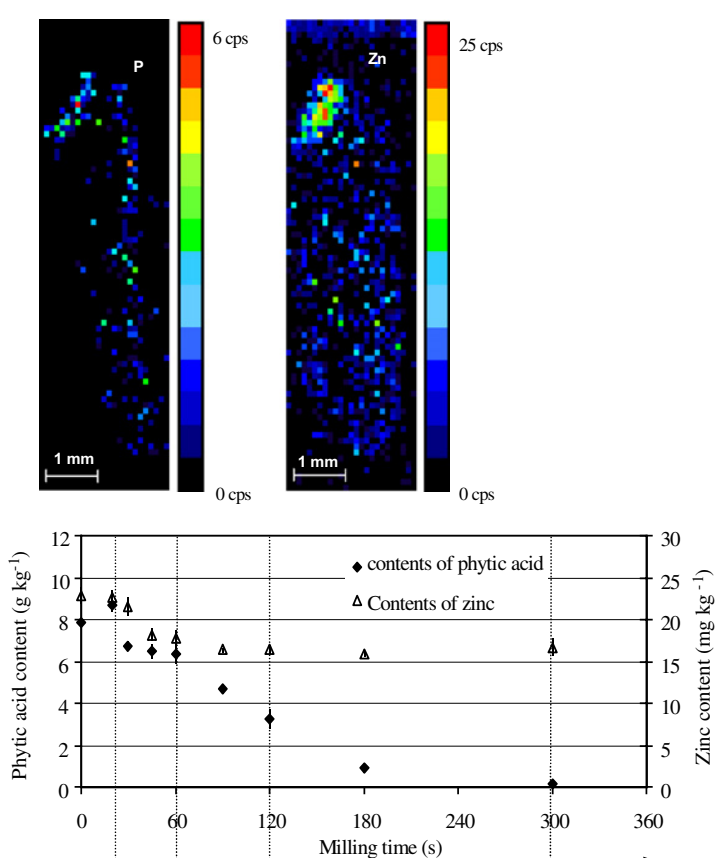

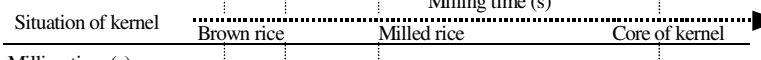

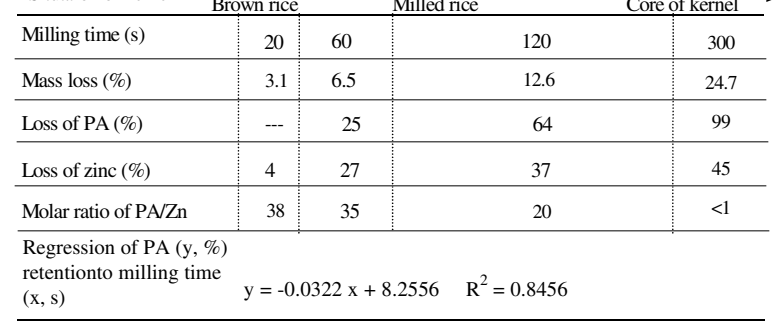

Fig. 2. (a) Distribution of phytic acid and Zn in Bijing 37 (short-grain). (b) Distribution of phytic acid and Zn in Zhongyou 752 (medium-grain). (c) Distribution of phytic acid and $\mathrm{Zn}$ in Ganwanxian 30 (long-grain). 
$40-50 \%$ of PA was located in the peripheral layers of brown rice, representing $13-15 \%$ of kernel weight. The distribution of PA observed from milling experiments is very well supported by images obtained from X-ray scanning. Differences in the distribution of PA location in cultivars mainly occurred in the outermost layer. In this region, distribution of PA in B37 and Z752 was similar, and relatively even at the outermost surface with a steep decrease inward. However, the distribution in G30 was quite different, showing a steep decrease already at the outermost surface layer, followed by a relatively even distribution. This distribution pattern was similar to the distribution of phosphorus in other rice cultivars (Bajaj et al., 1989). The perisperm is another layer of the kernel, removed at the interval of milling duration from 60 to 120 s. PA located here varied by $20-40 \%$, with weight per cent at $4-6 \%$ in different cultivars.

The distribution of $\mathrm{Zn}$ in the three cultivars was different. For B37, distribution of $\mathrm{Zn}$ was relatively even in the layer representing $30 \%$ of the total kernel weight, with a steep decrease in the next region, and followed with another even distribution in the central part. In contrast, in Z752, a steep decrease of $\mathrm{Zn}$ occurred at the sub-surface layer, at the milling interval from 30 to $60 \mathrm{~s}$ (occupied about $4 \%$ of total weight of kernel), and with an even distribution in other parts. For G30, the distribution of $\mathrm{Zn}$ was relatively even from the surface to the central part of the kernel. The highest decrease occurred at the interval of $60-120$ s. Further analysis of regression showed there was no correlation between $\mathrm{Zn}$ contents and milling duration. Figs. 2 also showed that more than $60-70 \%$ of total PA was located in the $10 \%$ of surface layer, and less than $40 \%$ of $\mathrm{Zn}$ was in the same layer. The different distribution patterns of phosphorus and $\mathrm{Zn}$ should enable an optimized milling, removing as much as possible phytate while retaining relevant levels (at least $50 \%$ ) of $\mathrm{Zn}$.

Molar ratios of PA to $\mathrm{Zn}$ varied with regions in kernel and cultivars. For all cultivars, only when more than $20 \%$ of outer layer was removed, molar ratios of PA to $\mathrm{Zn}$ could decrease to less than 1 . This was achieved only after $300 \mathrm{~s}$ milling, which is considerably longer than the standard commercial practice.

\section{Discussion}

Milling consequences, such as mass loss and breakage, could be affected by intrinsic factors (e.g., cultivar, kernel shape) as well as extrinsic factors (e.g., milling equipment). Under identical processing conditions, rice can display different processing properties. These can be caused by cultivar, maturity, and cultivating conditions, and can influence mass loss and breakage because of different shape, hardness of kernels, and thickness of the aleurone layer (Juliano, 1972; Zhou, 2003). Different bran loss rates by milling have been attributed to shape and hardness of grains, as well as pericarp thickness, oil bodies, cellulose, and hemicelluloses in bran layers (Juliano,
1972; Mohapatra and Bal, 2004; Singh et al., 2000; Singh Gujral et al., 2002). These would contribute to the differences observed for the three cultivars and the higher mass loss rate after short milling periods. Cultivars differ in thickness of the aleurone layer and in hardness distribution in the endosperm. Japonica (bold or coarse short-grain) kernels tend to have more cell layers than indica (slender long- or medium-grain) kernels. The central core and the mesocarp in indica and japonica, respectively, are hard, and kernel hardness is negatively correlated to length-tobreadth ratio (Juliano, 1972). Combined effects of such factors may have caused the relatively high mass loss of Z752 from milling.

In addition to the effect of equipment and process conditions, the composition, structure and thickness of rice kernels also affect the extent of breakage from milling (Siebenmorgen and Qin, 2005; Zhou, 2003). Whereas breakage could not be related to kernel width or length (Siebenmorgen and Qin, 2005), the susceptibility to relative humidity and fissuring could play a role in breakage (Lloyd and Siebenmorgen, 1999). Further investigation is required to help understand the mechanism for the high extent of breakage from milling in Z752.

$\mathrm{PA}$ is an important storage of phosphorus and minerals present in seeds. It usually occurs as a mixed salt of potassium and magnesium, and may also contain calcium, $\mathrm{Zn}$ and/or iron. Phytate has a different accumulation pattern from protein reserves which are mainly deposited within the numerous protein bodies in seed storage cells (Liu et al., 2004, 2005b). Studies on japonica rice indicated that PA levels were not related to protein levels, which were significantly influenced by genetic and environmental factors (Juliano, 1972; Liu et al., 2005a, b). Our milling experiment indicated that about $25 \%$ of the PA is located in the perisperm of the kernel, which differs from earlier findings that PA was only present in the aleurone layer after embryo removal (Liu et al., 2004). This difference suggests that although PA is approximately located in the outer layer of kernel, the precise distribution might differ among rice cultivars. In order to obtain milled rice with minimum weight losses but maximum removal of PA, the distribution of PA in the kernel should be established first, and this should form the basis to determine the appropriate milling treatment. Our X-ray microscope images indicate that in absolute terms, very little phosphorus is located in the embryo itself, which differs from the observation made earlier (Liu et al., 2004) that phosphorus concentration in embryos was about five times higher than in whole kernels. Both abrasive milling experiments and $\mathrm{X}$-ray images indicate that $\mathrm{Zn}$ was not mainly located in rice bran, unlike total ash or other minerals (Dikeman et al., 1980; Doesthale et al., 1979; Kennedy et al., 2002; Resurreccion et al., 1979). From our X-ray images, it can be observed that the embryo has the highest concentration of $\mathrm{Zn}$. It, however, represents a very small fraction of the total grain and, in absolute terms, does not contribute very much to the total $\mathrm{Zn}$ in milled rice. 
The different distributions of PA and $\mathrm{Zn}$ in rice kernels confirmed earlier statements that PA is primarily present in the potassium or magnesium form instead of the $\mathrm{Zn}$ form (Dikeman et al., 1980). Further research is required to assess the effects of other factors such as environmental conditions and agricultural practice, on the distribution of $\mathrm{PA}$ and minerals in rice.

\section{Conclusion}

From this study we conclude that milling characteristics, including mass loss and breakage, varied among the rice cultivars having different kernel shapes. This indicates an opportunity for optimized milling, dedicated to improve the quality of white rice.

In the cultivars studied, we observed that whereas the distribution of PA differed, most of it was located in the outermost layer. In contrast, $\mathrm{Zn}$ distribution in the three cultivars was quite similar, characterized by an even distribution throughout the kernel with the exception of a higher concentration in the embryo. The results give us the possibility to process brown rice to obtain low PA contents at a relatively high $\mathrm{Zn}$ content.

\section{Acknowledgements}

Financial support was provided by Wageningen University through the North-South Interdisciplinary Research and Education Fund (INREF). We gratefully acknowledge the assistance of Dr. Adriaan van Aelst with the preparation of rice kernels for microscopy, and of Dr. Zengling Yang with the digestion of samples and AAS analysis.

\section{References}

Bajaj, M., Arora, C.L., Chhibba, I.M., Sidhu, J.S., 1989. Extended milling of Indian rice. III. Effect on mineral composition. Chemie Mikrobiologie Technologie der Lebensmittel 12, 58-60.

Bryant, R.J., Dorsch, J.A., Rutger, J.N., Roboy, V., 2005. Phosphorus and mineral concentration in whole grain and milled low phytic acid (lpa) 1-1 rice. Cereal Chemistry 82, 517-522.

Centre of China Crop Science and Technology, 2006. 〈http://www. cropchina.com/old/food/zy751.htm > (visited September 2006).

Chen, H., Siebenmorgen, T.J., 1997. Effect of rice thickness in degree of milling and associated optical measurements. Cereal Chemistry 74, $821-825$.

Chen, H., Siebenmorgen, T.J., Griffin, K., 1998. Quality characteristics of long-grain rice milled in two commercial systems. Cereal Chemistry 75 , 560-565.

CHISA, 2002. China Industrial Standards Authority: Rice, China Industrial Standard (Agriculture) NY/T 593-2002.

D’Ilio, S., Alessandrelli, M., Cresti, R., Forte, G., Caroli, S., 2002. Arsenic contents of various types of rice as determined by plasma based techniques. Microchemical Journal 73, 195-201.

Dikeman, E., Bechtel, D.B., Pomeranz, Y., 1980. Distribution of elements in the rice kernel determined by $\mathrm{X}$-ray analysis and atomic absorption spectroscopy. Cereal Chemistry 58, 148-152.

Doesthale, Y.G., Devara, S., Rao, S., Belavady, B., 1979. Effect of milling on mineral and trace element composition of raw and parboiled rice. Journal of the Science of Food and Agriculture 30, 40-46.
Emoto, T., Sato, Y., Konishi, Y., Ding, X., Tsuji, K., 2004. Development and applications of grazing exit micro $\mathrm{X}$-ray fluorescence instrument using a polycapillary X-ray lens. Spectrochimica Acta Part B 59, 1291-1294.

Heinemann, R.J.B., Fagundes, P.L., Pinto, E.A., Penteado, M.V.C., Lanfer-Marquez, U.M., 2005. Comparative study of nutrient composition of commercial brown, parboiled and milled rice from Brazil. Journal of Food Composition and Analysis 18, 287-296.

Information of Jiangxi foodstuff-oil and soil-fertilizer, 2006. 〈http:// lytf.jxagri.gov.cn/ShowDetailZD.Asp?ID = 7150 $\rangle$ (visited September 2006).

Itani, T., Tamaki, M., Arai, E., Horino, T., 2002. Distribution of amylose, nitrogen, and minerals in rice kernels with various characters. Journal of Agricultural and Food Chemistry 50, 5326-5332.

Juliano, B.O., 1972. The rice caryopsis and its composition. In: Houston, D.F. (Ed.), Rice Chemistry and Technology. Monograph Series. American Association of Cereal Chemists, St. Paul, MN, pp. 16-74.

Kennedy, B.M., Schelstraete, M., 1975. Chemical, physical and nutritional properties of high-protein flours and residual kernel from the overmilling of uncoated milled rice. Cereal Chemistry 52, $173-182$.

Kennedy, G., Burlingame, B., Nguyen, N., 2002. Nutrient impact assessment of rice in major rice-consuming countries. International Rice Commission Newsletter 51, 33-41.

Konishi, Y., Hirano, S., Tsuboi, H., Wada, M., 2004. Distribution of minerals in quinoa (Chenopodium quinoa Willd.) seeds. Bioscience, Biotechnology and Biochemistry 68, 231-234.

Liang, J., Han, B.-Z., Han, L., Nout, M.J.R., Hamer, R.J., 2007. Iron, zinc, and phytic acid content of selected rice varieties from China. Journal of the Science of Food and Agriculture 87, 504-510.

Liu, Z., Cheng, F., Zhang, G., 2005a. Grain phytic acid content in japonica rice as affected by cultivar and environment and its relation to protein content. Food Chemistry 89, 49-52.

Liu, Z.H., Cheng, F.M., Cheng, W.D., Zhang, G.P., 2005b. Positional variations in phytic acid and protein content within a panicle of japonica rice. Journal of Cereal Science 41, 297-303.

Liu, J.C., Ockenden, I., Truax, M., Lott, J.N.A., 2004. Phytic acidphosphorus and other nutritionally important mineral nutrient elements in grains of wild-type and low phytic acid (lpa1-1) rice. Seed Science Research 14, 109-116.

Lloyd, B.J., Siebenmorgen, T.J., 1999. Environmental conditions causing milled rice kernel breakage in medium-grain varieties. Cereal Chemistry 76, 426-427.

Ma, G., Jin, Y., Piao, J., Kok, F., Bonnema, G., Jacobsen, E., 2005. Phytate, calcium, iron, and zinc contents and their molar ratios in food commonly consumed in China. Journal of Agricultural and Food Chemistry 53, 10285-10290.

Mohapatra, D., Bal, S., 2004. Wear of rice in an abrasive milling operation, part 1: prediction of degree of milling. Biosystems Engineering 88, 337-342.

Nijsse, J., Van Aelst, A.C., 1999. Cryo-planing for cryo-scanning electron microscopy. Scanning 21, 372-378.

Park, J.K., Kim, S.S., Kim, K.O., 2001. Effect of milling ratio on sensory properties of cooked rice and on physicochemical properties of milled and cooked rice. Cereal Chemistry 78, 151-156.

Perdon, A.A., Siebenmorgen, T.J., Mauromoustakos, A., Griffin, V.K., Johnson, E.R., 2001. Degree of milling effect on rice pasting properties. Cereal Chemistry 78, 205-209.

Resurreccion, A.P., Juliano, B.O., Tanaka, Y., 1979. Nutrient content and distribution in milling fractions of rice grain. Journal of the Science of Food and Agriculture 30, 475-481.

Siebenmorgen, T.J., Qin, G., 2005. Relating rice kernel breaking force distributions to milling quality. Transactions of the ASAE 48, 223-228.

Singh, N., Singh, H., Kaur, K., Singh Bakshi, M., 2000. Relationship between the degree of milling, ash distribution pattern and conductivity in brown rice. Food Chemistry 69, 147-151. 
Singh Gujral, H., Singh, J., Singh Sidhu, J., Singh, N., 2002. Effect of milling variables on the degree of milling of unparboiled and parboiled rice. International Journal of Food Science and Technology 5, 193.

Song, B.H., Kim, D.Y., Kim, S.K., Kim, Y.D., Choi, K.S., 1988. Distribution of minerals within the degermed brown rice kernel. Journal of Korean Agricultural Chemistry 31, 162-168.

Tabekhia, M.M., Luh, B.S., 1979. Effect of milling on macro and micro minerals and phytate of rice. Deutsche Lebensmittel-Rundschau 75, 57-62.

Tran, T.U., Suzuki, K., Okadome, H., Homma, S., Ohtsubo, K., 2004. Analysis of the tastes of brown rice and milled rice with different milling yields using a taste sensing system. Food Chemistry 88, $557-566$.
Vasca, E., Materazzi, S., Caruso, T., Milano, O., Fontanella, C., Manfredi, C., 2002. Complex formation between phytic acid and divalent metal ions: a solution equilibria and solid state investigation. Analytical and Bioanalytical Chemistry 374, 173-178.

Villareal, C.P., Maranville, J.W., Juliano, B.O., 1991. Nutrient content and retention during milling of brown rices from the International Rice Research Institute. Cereal Chemistry 68, 437-439.

Yu, B., Zhang, S., Gu, S., Ye, Y., Luo, H., 2001. Selection and application research of high-yielding new japonica rice variety-Bijing 37. Review of China Agricultural Science and Technology 3, 16-19.

Zhou, H., 2003. Cereals Science Principle. China Light Industrial Press, Beijing, pp. 1-3, 196-217 (in Chinese). 